\title{
The role of qualitative research in management
}

\author{
C. Orpen \\ School of Management, Deakin University, Victoria, 3217, Australia
}

Received 7 April 1987; accepted 16 May 1987

\begin{abstract}
It is argued that there are currently two separate research approaches to behaviour in organizations; the qualitative approach and the quantitative approach, each with their own framework, criteria of proof, and accepted procedures. Reasons for the dominance of the quantitative approach and the renewed interest in the qualitative approach are presented. Implications for future research in organizational behaviour are developed. There is a need for more multi-approach research efforts and for a conceptual scheme that will locate the two approaches in relation to one another.
\end{abstract}

\begin{abstract}
Daar word aangevoer dat daar tans twee verskillende benaderings tot gedrag in organisasies bestaan; die kwalitatiewe- en die kwantitatiewe benadering, elk met sy eie raamwerk, bewyse en aanvaarde prosedures. Redes word gegee vir die dominansie van die kwantitatiewe benadering asook vir die hernieude belangstelling in die kwalitatiewe benadering. Implikasies daarvan vir verdere navorsing oor organisatoriese gedrag word gegee. Daar bestaan ' $n$ behoefte na meer gekombineerde navorsingspogings en ' $n$ skema wat die twee benaderings sal weergee in verhouding tot mekaar.
\end{abstract}

As will quickly become apparent from reading any text, there are a number of different ways in which the human aspects of managing can be investigated. As a result, there is the potential for a much greater degree of disagreement, even mutual ignorance, among investigators of organizational behaviour than among researchers in disciplines where there is consensus about the way in which problems should be investigated. According to van Maanen (1979) and Filstead (1970), the basic difference underlying the various approaches to studying organizational behaviour is whether or not they are qualitative or quantitative in nature. It is this difference that, in their view, tends to divide students of organizational behaviour into 'opposing camps', that are often ignorant of what each other is doing and frequently deny the validity of each other's approach as well. It is my view that over the past few decades this has led to a 'debilitating schism' within the discipline, between those who support quantitative approaches and their opponents who believe only qualitative approaches are really capable of improving our understanding of people's behaviour in organizations.

\section{What is qualitative research?}

Like many things, qualitative research is difficult to define precisely but is nevertheless immediately recognizable, especially when it is contrasted with research that is obviously quantitative. One reason why it is difficult to produce a definition that captures the 'essence' of qualitative research is that such a variety of techniques have, at one time or another, been employed by researchers who believe they are doing qualitative, as opposed to quantitative, research, such as role playing, depth interviews, unobtrusive observations, participant observation, case studies and autobiographies. Another is that the outcomes of qualitative research do not conform to a 'standard pattern that can be identified as being of one type rather than another. All they have in common is that they are detailed descriptions of events, people and situations in organizations, together with attempts to explain what is going on. And this is not something that can be picked out and labelled in any straightforward sense. Given these difficulties, it is better to 'define' qualitative research by contrasting it with quantitative research, a type of research that can be more easily defined.

As van Maanen (1979) makes clear, the objective of the qualitative researcher is to uncover the meaning, not just the frequency, of human events in organizations. The qualitative researcher is permanently concerned with the significance of events, situations, and objects to people, in the belief that only if we know what things mean to particular people will we be able to make sense of their behaviours. Qualitative research adopts a more holistic and broader perspective than does quantitative research. It attempts to 'explain' the actions of people in organizations by showing how they are affected by the total context in which they occur, and in turn how they affect the various elements that constitute this context. Contrary to what happens in quantitative research, in qualitative research there is no attempt to isolate what is being studied and to alter or vary it in any way (Smith, 1975; Patten, 1980).

The aim is to study behaviour as it occurs, naturally and ordinarily, something that requires a description of the context in which the behaviour takes place and an ability to view the behaviours from the point of view of the agent, him or herself. In order to achieve these goals, the qualitative researcher, to an extent not required of someone engaged in quantitative research, needs direct, firsthand, and fairly intimate knowledge of the research setting and the people whose behaviours he or she is trying to understand (e.g., Lofland, 1980). As a result, qualitative research typically takes longer and involves more effort from the researcher, besides depending far more on his capacity to sympathetically understand things from other people's point of view. As studies by Light (1980), Pettigrew (1973) and Jick (1980) show clearly, qualitative research consists of much fuller 
descriptions of people, situations, and events, with a lot more depth and detail than reports from quantitative research.

The quantitative researcher follows Popper's (1968) prescription for doing science, by relying heavily on deduction in the development of hypotheses to be tested. Typically, he or she starts with a theory or set of general propositions about behaviour in organizations from which specific predictions are developed. These are then tested by means of an experiment or survey, depending on the purpose of the researcher. However, as Mintzberg (1979) has shown, it is inductive rather than deductive logic that plays the more important part in qualitative research. In such research. the investigator's main concern is with arguing from the particular to the more general, of producing generalizations from the variety of instances of behaviours, events, and situations that form the 'data' of the investigation.

According to Mintzberg (1979), there are two essential steps in this process of inductive research, neither of which are present, or brought out, in quantitative research to the same extent. First, there is the process of tracking down patterns and consistencies in the data by the qualitative researcher; of searching through the data looking for leads and following them up (a process Mintzberg called 'detective work'). Second, there is the process of 'jumping' from the specific data to an idea or concept that covers a much wider terrain, of breaking away from the data to describe something new or different (but always more general) that is suggested by the data, but not logically deduced from it (a process Mintzberg called 'creative leaping'). This requires a controlled imagination of the kind, he feels, is stimulated by doing qualitative, as opposed to quantitative research.

The final difference between the two kinds of research that will have to suffice to prove my point that we indeed are dealing with two different approaches to research is that qualitative research moves backwards and forwards in a way that quantitative research does not. For instance, in quantitative research a two-step procedure is typically followed, in which hypotheses are developed from theory and then tested by means of an experiment or survey. The testing process follows the hypothesis development stage and completes the investigation. The researcher then tries to explain the results obtained with the existing data. There is no attempt, as part of the same investigation, to go back and collect further data, or even reanalyze the data from a different perspective (Sommer \& Sommer, 1980).

In contrast, qualitative researchers typically follow a circular process of collecting data, developing rough hypotheses from the regularities they observe, and then returning to the original or new data to 'try out' their hypotheses. The process is characterized by a provisional, tentative, approach that goes this way or that depending on what the researcher learns during the process of investigation (Brogdan \& Taylor, 1975). It stands in sharp contrast to the requirements of most quantitative research, that certain established procedures be followed to improve the chances of drawing valid inferences from the experimental or survey findings. As Kaplan (1964) illustrates so clearly, the emphasis in quantitative research is on the collection of numerical data using standardized instruments, following pre-established steps or programmes.

\section{The dominant position of the quantitative research approach}

Although qualitative and quantitative research are not mutually exclusive, there can be little doubt that quantitative research has for some time enjoyed a dominant position within the discipline. Researchers in the human aspects of management are expected to conduct quantitative research because, so they are told, it is the kind of research that stands the best chance of producing valid and useful knowledge (e.g., Organ \& Bateman, 1986; Baron, 1984). There are a number of reasons for the ascendancy of quantitative research, for its tendency to drive out qualitative research, among which the following appear most widespread. First, the fact that it is difficult, if not impossible, in qualitative research to disentangle the unique aspect of what is investigated from more generalizable ones, has frightened off some researchers. Most researchers, given their training and background, prefer to be able to specify, more accurately than can be done in qualitative research, to what extent their findings will be valid over a fairly broad range of instances (Stone, 1978; Scott, 1975).

Second, there is a natural curiosity on the part of researchers to want to see how their results compare with those of others doing similar, although not identical, research. Lack of quantification makes comparisons of this kind much less reliable and accurate, making it less likely, in the views of many researchers, that their qualitative study will be replicated or even looked at by other researchers (Organ \& Bateman, 1986; Kerlinger, 1973).

Third, techniques for analyzing quantitative data quickly and accurately have improved with the greater availability of personal computers and more sophisticated software packages. This has encouraged many researchers to conduct quantitative research that produces data amenable to such analyses, rather than the more time-consuming alternative of doing qualitative research.

Fourth, the prevailing self-image of management researchers - as scientists doing objective research still helps explain the reluctance of some to do research that can appear 'unscientific'. They are worried that the involvement in particular organizations, that is the hallmark of qualitative research, will cause them to lose the neutrality and objectivity that they believe necessary to do scientific research and to remain faithful to their profession (Argyris, 1980; Boalt, 1980). Finally, both the leading journals and universities have reward systems that encourage researchers to conduct quantitative studies employing tight experimental or survey designs. The major journals favor deductive-analytic research 
that sets out to test specific theory-generated hypotheses, rather than qualitative studies that are inductive and holistic in character. The leading universities, at least in the United States, have a 'publish or perish' policy, although seldom acknowledged as such, that encourages younger academics to do quantitative research, that is not only quicker and easier to do, but for which there are also more publication outlets than qualitative research (Brogdan \& Taylor, 1975; Filstead, 1970).

\section{Renowed interest in the qualitative research epprosch}

Nevertheless, there has, over recent years, been a renewed interest in qualitative research and its techniques. Since the 1970 s there has been a marked increase in the number of books and articles dealing with qualitative research and techniques favoured by its practitioners, such as ethnography, participant observation, depth interviews, case clustering, unobtrusive measures, and documentary analysis (e.g., Manning, 1977; Douglas, 1980; Johnson, 1985; Bouchard, 1985; Garfinkel, 1985). It appears as if it is now acceptable within the discipline to conduct qualitative research, such research is believed capable of producing results that deserve close attention at least. What are the reasons for this increased attention to qualitative research? Why has it become respectable at last?

Probably the most pervasive reason for the renewed interest in qualitative research is the growing distrust and suspicion with the procedures employed by quantitative researchers. In particular, a growing number of commentators have criticized the extreme reliance of so much quantitative research on pencil-and-paper surveys, formal interviews and laboratory experiments (e.g., Argyris, 1980; Brogdan \& Taylor, 1975). Increasingly, the problems of producing valid and useful findings from these procedures, instead of being hidden in footnotes or qualifications, are being given a prominent place in articles and books in the field. Pencil-and-paper surveys are criticized for failing to deal with the problem of nonrespondent bias. Because of consistent differences between subjects who respond and those who fail to do so, it is very difficult, if impossible, to generalize the results to different samples from those used in the first place. There is also the difficulty, in surveys, of uncovering what people mean by their responses and of finding out how they interpret the various questions, something one needs to know if one is to really understand why particular people think, feel and act like they do (e.g., Garfinkel, 1985; Lofland, 1976). In the case of formal interviews, the fact that respondents are typically forced to think and respond in terms defined by the researchers, not by themselves, is held by many to make it impossible for them to really convey what is responsible for their being like they are and behaving like they do (e.g., Patten, 1980; Smith, 1975). In addition, there are semantic problems and difficulties in assessing how much the respondent is affected by the interview situation in formal interviews, mainly caused by trying to shortcut the process of getting to know people by spending time with them in their own world (Denzin, 1972; Barker, 1976). As regards experimental research, the artificiality of most laboratory settings, the reactivity of subjects, and the consequent lack of generalizability of findings emerging from such research, are criticisms that are now well-known and widelyaccepted (Baron, 1984; Organ \& Bateman, 1986). The cumulative effect of these objections has been to cause quite a few researchers to adopt qualitative approaches in their investigations, in the hope thereby of overcoming, or reducing, these difficulties with surveys, formal interviews and experiments.

Another reason why qualitative approaches have become the object of greater interest is because more researchers now believe that the essential features of organizational behaviour are lost or altered if the behaviour to be studied is broken down into simpler components, whose effects on each other are then examined in controlled settings as required by quantitative research techniques. Recent advances in systems theory (Kast \& Rosenzweig, 1984) and the adoption of contingency theory perspectives (Hellriegel \& Slocum, 1983) has led a growing number of researchers to accept that behaviour in organizations must be studied naturally, as it occurs, in real life settings, in all its complexity and richness, if it is to be properly understood. It is also recognized, again to a greater extent than previously, that the gestalt or totality of behaviour in its setting needs to be grasped if one wants to appreciate why people behave like they do (e.g., Douglas, 1980; Garfinkel, 1985). Phenomena like leadership, conflict in organizations, job performance, individual stress and even selection and training cannot, according to an increasing number of researchers (e.g., Lofland, 1976; Denzin, 1972; Argyris, 1980), be properly understood by limiting one's attention to a few variables such as organization structure, job attributes, individual needs, as required by quantitative research techniques. Two things are needed, they argue, to provide the understanding of those phenomena that is desired. First of all, there must be recognition that we are dealing with a complex, situational phenomenon that is influenced by (and influence) not just these few variables but by many others whose nature and number will vary depending on circumstances. Secondly, researchers must realize that, because of the nature of organizational behaviour, it needs to be studied by qualitative techniques that permit the researcher to get close to the data, to study it in its natural setting, and to come to know well both the individual and the organization. As Mintzberg (1979: 582) puts it, 'Above all, measurements need to be in real organizational terms which means measuring things as they really happen in organizations, as people experience them, and not violate the organization by forcing it into abstract categories that have nothing to do with how it functions'.

The third reason why there has been renewed interest in qualitative research and its techniques has to do with 
the limitations of experiments and surveys - the chief tools of the quantitative researcher - as ways of establishing why people act like they do in organizations. For instance, in surveys researchers decide early on, when deciding upon their investigation, what variables they think will vary with, or be related to, certain behaviours and how they will be measured. If expected results are obtained, they are then attributed to these variables; if not, then researchers are left to guess what may be responsible for their findings. The trouble with surveys is that there is always the chance, even when expected results are obtained, that the behaviour is not due to what the researchers had measured, but to something else instead: And there is no way of finding this out, short of getting into the organization, talking to the particular people, and treating their answers as the independent variable which is to do qualitative research. Moreover, one can hardly speak of really understanding behaviour when one only knows one or two things to which it is related, but this is all that surveys can reveal, not even whether those relationships are caused by some third unmeasured variable. In experiments, there is always the possibility that what is causing the positive results is not the manipulated variable, but how the subjects interpreted the total situation, including their perceptions of why they were recruited in the first place, what sort of results the experimenter is looking for, and how a 'good' subject should behave. These interpretations may differ consistently across the experimental groups, thus affording another explanation for the findings: But this is not something the experimenter would know, without going outside the experiment itself and doing qualitative research. In short, quantitative researchers are left to speculate why they got negative results and whether their preferred explanations for positive results are the only or best ones, but without the benefit of properly getting to know their subjects and their situation (Douglas, 1980; Lofland, 1976). It is, I believe, because of these kinds of concerns that a growing number of researchers are turning to qualitative research in their search for valid and useful findings about organizational behaviour.

Despite the increasing popularity of qualitative research, it is an approach with several weaknesses. For instance, the samples used in many qualitative research studies are small and unrepresentative, making it difficult to know how generalizable the results are. It is typically very difficult to classify the data gathered in qualitative research into categories that can be usefully employed in different circumstances (e.g., Stone, 1978). The methodology employed in many qualitative studies is subjective, and the findings reached based on the personal views of the researchers, to an extent that is impossible to assess (Kerlinger, 1973). Finally, because of the time and effort involved in doing qualitative research, it is difficult to find sufficient a number of researchers willing to do the necessary work, but without which our knowledge will remain sketchy and incomplete (Smith, 1975).

\section{Implications for the future of organizational behaviour research}

Part of the reason for juxtaposing the two approaches to the development of knowledge in the way that has been done in this article, is to make it apparent that their respective strengths and weaknesses are mirroropposites of each other. For example, if qualitative research stresses subjectivity, it is the opposite for quantitative research. If qualitative research stresses validity in the understanding of behaviours in organizations, quantitative research stresses the reliability of the means by which this behaviour is measured. And if qualitative research concentrates on the inner experiences of a subject as viewed by both the research and the participants, qualitative research assumes that it is more productive to concentrate on observable deeds and expressed words. If this is the case, what conclusions can be drawn from this analysis of the two approaches to gaining knowledge about the human aspect of managing? I believe there are at least four conclusions that follow fairly straightforwardly from the analyses, each with implications for the future development of the discipline.

First, we are faced with a situation in which two separate paradigms exist for gaining an understanding of organization behaviour, each with its own logic and assumptions and established procedures. Further, so long as neither paradigm finds its assumptions for doing research unsuitable, each will continue to develop along its own path and from within its own epistemological framework. My prediction is that the two approaches, because they are so different, will continue alongside each other without any blending of the two together in some kind of grand synthesis.

Secondly, because the two approaches have weaknesses and strengths that are the opposite of each other, I believe more research efforts should try to employ quantitative and qualitative approaches within the same study. Based on the arguments developed in this paper, there should be many more attempts to use the insights from one approach to improve what we learn from the other, and for this to be done as part of the same piece of research. The fact that quantitative and qualitative research are in disagreement over their basic assumptions and ways of collecting and interpreting data need not force the researchers to make an either/or decision. On the contrary, I feel that the existence of the two approaches should be seen as an opportunity to use more than one approach in doing research, using the two to enhance and refine what we could learn from one alone.

Thirdly, the various techniques that have been developed for combining the two approaches in the most fruitful way possible should be given much more attention than at present. For instance, the results from surveys can be compared with interviews of 'extreme' respondents to the survey, as done so effectively in The Authoritarian Personality (Adorno, Frenkel-Brunswik, Sanford \& Levinson, 1950). Again, the subjectivity of case analyses can be reduced by having several 
competent investigators 'analyze' the same firm or group of people, thus increasing the number of observations of the same event. Case clustering techniques can be employed to create more 'degrees of freedom' in qualitative case studies, by requiring the researchers to systematically compare the results of different, but similar, case reports (McCintock, Brannon \& MaynardMoody, 1979). The act of data collection can be separated from that of interpretation by having them done by two different people (Smith, 1975). The procedures involved in such 'triangulation' techniques (Jick, 1979) need to be spelled out in detail and followed by researchers attempting to employ more than one approach in investigating organization behaviour.

Fourthly, given the continued existence of these two approaches, as fairly independent ways of producing knowledge about human aspects of managing, with their own rules of evidence and distinctive procedures, it is my guess that we shall see more divergences, greater arguments and further complications, rather than answers and resolutions as our search for valid knowledge continues. It is my guess, based on the analysis in this paper, that we shall see improvements in research within each approach, but unfortunately only a few attempts to integrate the two approaches together in a creative fashion. As a result, these improvements will, I believe, paradoxically lead to less consensus about research problems, methods and interpretations of results, and to a more complicated, but more complete, view of human behaviour in organizations and how it should be studied. This is partly because progress in research, especially when more than one paradigm exists within a discipline, tends to reveal the inadequacy of current knowledge and accepted ideas about generating it. It is partly because we still lack an appropriate language and conceptual science of locating these two approaches in relation to one another that there will be many false starts and dead ends for those who choose to work in this area.

\section{References}

Adorno, T.W., Frenkel-Brunswik, E., Sanford, R. \& Levinson, F.W. 1950. The authoritarian personality. New York: Harper and Row.

Argyris, C. 1980. The inner contradictions of rigorous research. New York: Academic Press.

Baron, R.A. 1984. Behavior in orcanizations. Boston, MA: Allyn and Bacon.

Barker, R. 1976. Ecological psychology. Stanford, CA: Stanford University Press.

Boalt, G. 1980. The sociology of research. Carbondale, IL: Southern Illinois University Press.

Bouchard, T.J. 1985. Unobtrusive weakness: An inventory of uses. Soc. Methods Res., vol.4, 267-300.

Brogdan, R., \& Taylor, S.J. 1975. Introduction to qualitative research methods. New York: Wiley.

Denzin, N.K. 1972. The research act. New York: McGraw-Hill.
Douglas, J.D. 1980. Understanding social life. New York: McGraw-Hill.

Filstead, R. 1970. Qualitative methodology. Chicago, IL: Rand-McNally.

Garfinkel, H. 1985. Studies in ethnomethodology. Englewood Cliffs, NJ: Prentice-Hall.

Hellriegel, D. \& Slocum, J.W. 1983. Organizational behaviour: A contingency perspective. St. Paul, MN: West Publishing.

Jick, T.D. 1980. Process and impact of a merger: Individual and organizational perspectives. Doctoral dissertation: New York State School of Industrial and Labor Relations, Cornell University.

Jick, T.D. 1979. Mixing qualitative and quantitative methods: Triangulation in action. Admin. Sci. Quart., vol.24, 602-611.

Johnson, J. 1985. Doing fieldwork. New York: Free Press.

Kaplan, A. 1964. The conduct of inquiry. San Francisco, CA: Chandler Publishers.

Kast, F. \& Rosenzweig, M. 1984. Organizations and management: A systems approach. New York: McGraw-Hill.

Kerlinger, F. 1973. Foundations of behavioural research. New York: Holt, Rhinehart and Winston.

Light, D.J. 1980. Becoming psychiatrists: The professional transformation of self. New York: Norton.

Lofland, J. 1976. Doing social life: The qualitative study of human behavior in natural settings. New York: Wiley.

Manning, K. 1977. Police work: The social organization of policing. Cambridge, MA: Massachusetts Institute of Technology Press.

McCintock, C.C., Brannon, D. \& Maynard-Moody, S. 1979. Applying the logic of sample surveys to qualitative case studies: The case cluster method. Admin. Sci. Quart., vol. 24, 612-629.

Mintzberg, H. 1979. An emerging strategy of 'direct' research. Admin. Sci. Quart. vol.26, 583-589.

Organ, D. \& Bateman, T.W. 1986. Organizational behaviour. Plano, TX: Business Publications.

Patten, W.H. 1980. Qualitative evaluation methods. Beverly Hills, CA: Sage.

Pettigrew, A. 1973. The politics of organizational decision-making. London: Tavistock.

Popper, K. 1968. The logic of scientific discovery. New York: Science Editions.

Scott, W.E. 1975. The development of knowledge in organizational behaviour. Decision Sci., vol.6, 141-165

Smith, H. 1975. Qualitative research methods. New York: McGraw-Hill.

Sommer, R. \& Sommer, B. 1980. A practical guide to behavioural research. New York: Oxford University Press.

Stone, E. 1978. Research methods in organizational behavior. Santa Monica, Ca.: Goodyear.

Van Maanen, J. 1979. Reclaiming qualitative methods for organizational research. Admin. Sci. Quart., vol.26, 520-527. 